\title{
Thin Polyurethane Films of Polyhydroxysilicon Phthalocyanine and Bis-phthalocyanine Derivatives
}

\author{
Arun K. Sinha and Braja K. MandaL* \\ Department of Chemistry, Illinois Institute of Technology, \\ Chicago, Illinois 60616, U.S.A.
}

(Received April 5, 1995)

\begin{abstract}
A series of new silicon phthalocyanine $\left[\operatorname{SiPc}(\mathrm{OR})_{2}\right]$ and silicon bis-phthalocyanine $\left[\mathrm{RO}(\mathrm{SiPcO})_{2} \mathrm{R}\right]$ derivatives containing two or more hydroxyl groups was synthesized by axial etherification of $\left[\mathrm{PcSi}(\mathrm{OH})_{2}\right]$ or $\left[\mathrm{HO}(\mathrm{SiPcO})_{2} \mathrm{H}\right]$ with various polyfunctional alcohols, where $\mathrm{R}$ is a residue generated from the corresponding alcohol namely, triethanolamine, triethylene glycol or $N, N$-bis(2-hydroxyethyl isonicotinamide). These derivatives can be processed into thin polymeric films by reacting with isophorone diisocyanate. Many of the derivatives demonstrated high solubility in common organic solvents such as chloroform and dioxane, and exhibit low absorptions in the visible region.
\end{abstract}

KEY WORDS Polyhydroxysilicon Phthalocyanine and Bis-phthalocyanine /

Third-Order Nonlinear Optical Properties / Polyurethane /

Phthalocyanine $(\mathrm{Pc})$ derivatives have emerged as one of the most promising classes of materials in the area of nonlinear optics due to their large and ultrafast third-order optical nonlinearities. ${ }^{1-3}$ Although the molecular design requirements for practical third-order nonlinear optical materials are poorly understood, a combination of long $\pi$-conjugation length and low HOMO-LUMO gaps appear important. We and others have been interested in developing prototype devices for the protection of vision and sensors against short, intense laser pulses using Pc compounds due to their favorable transparency in the visible spectral range. ${ }^{4-7}$ To provide efficient vision protection, a material should possess (i) high nonresonant nonlinear optical susceptibility, $\chi^{(3)}$, which is directly proportional to the number density of the $\pi$-conjugated molecules (ii) be easily processable into thin films and (iii) be optically transparent in the visible region. However, the practical applicability of many
Pc derivatives is hindered due to their low solubility in common organic solvents and incompatibility with vinyl polymers which prevent thin film processing.

In the past decade, extensive effort has been made to produce soluble Pc derivatives. ${ }^{8-10}$ Most of the highly soluble Pc derivatives made so far contain either electron donor substituents such as alkyl, alkoxy or phenoxy groups, or electron withdrawing substituents such as sulfonyl or carboxyl groups at the peripheral positions. In recent years, several studies concerning the effects of peripheral substituents, ${ }^{11}$ additional conjugation such as in naphthalocyanine $\mathrm{e}^{1,12}$ and the central metal atom character ${ }^{7,13}$ on $\chi^{(3)}$ have been conducted. Results indicate that peripheral substituents greatly improve the solubility of Pc molecules and increase the absorption in the visible region and to some extent optical nonlinearities in molecules where electrons are permitted to flow in or out of cyclic $\pi$ -

\footnotetext{
* To whom all correspondence should be addressed.
} 
conjugated rings. In extended $\pi$-conjugated systems such as naphthalocyanine, absorption in the visible region increases dramatically while $\chi^{(3)}$ shows about a 5-10 times enhancement in its value. Similarly, the nature of the central metal atom plays an important role in tuning both optical nonlinearities and absorption in the visible region. For instance, $\chi^{(3)}$ of Pc increases about 15 times by changing the central metal atom from silicon to vanadium ${ }^{14}$ and similarly increases, albeit not as drastically, with a central heavy metal atom such as lead. ${ }^{15)}$ Axial derivatization through a metal atom such as silicon has also been found to increase the solubility of Pc molecules ${ }^{16-18}$ and have little to no effect on the absorption behavior in the visible region, depending on the axial substituents. In view of this, we have been interested in developing new types of axially modified Pc derivatives for laser vision protection devices.

Recently, we reported the synthesis of a new type of axially modified crosslinkable Pc derivatives that can be polymerized into thin fllms by thermally or photochemically. ${ }^{19}$ In this paper, we present a facile synthetic route for a new series of axially modified phthalocyanine monomers and dimers which contain two or more hydroxyl groups and comply with the processing and optical transparency requirements for materials to be used for vision protection from laster radiation.

\section{MATERIALS AND METHODS}

\section{Materials and Instrumentation}

Dihydroxysilicon phthalocyanine (DHPc), Dichlorosilicon phthalocyanine (DCPc), triethanolamine, triethylene glycol, $N, N$-bis(2hydroxyethyl isonicotinamide), and isophorone diisocyanate were purchased from Aldrich Chemical Co. and used as received. ${ }^{1} \mathrm{H}$ NMR and FAB-MS spectra of the compounds were obtained from outside facilities. All other characterizations were carried out using Perkin-Elmer systems: elemental analysis (PE-
2400); FT-IR (System-2000); TGA (Series-7); DSC (Series-7); UV-Vis (Lambda-19).

\section{Experimental Procedure}

Polyhydroxy Pc monomers and dimers were made by axial etherification of DHPc and dihydroxysilicon bis-phthalocyanine (DBPc), respectively, with a variety of polyfunctional alcohols.

General Procedure for the Preparation of Pc Monomers. In a typical experiment DHPc $(1 \mathrm{~g}$, $1.74 \mathrm{mmol})$ was added to a refluxing solution of triethanolamine $(5 \mathrm{~g}, 33.5 \mathrm{mmol})$ in $o$ dichlorobenzene $(40 \mathrm{ml})$ and pyridine $(5 \mathrm{ml})$ in a $100 \mathrm{ml}$ three-necked round-bottomed flask fitted with a condenser and a nitrogen inlet. After $1 \mathrm{~h}$ of refluxing, the mixture was filtered while hot to separate the compound from unreacted DHPc (separation of product was observed in some instances, in which case the residue was washed with $100 \mathrm{ml}$ chloroform). The filtrate on washing with $3 \times 100 \mathrm{ml}$ water followed by drying over $\mathrm{MgSO}_{4}$ and subsequent evaporation of solvent under reduced pressure gave a blue colored product 1a which was purified by recrystallization from a toluene: hexane mixture. Yield: $1.09 \mathrm{~g} \mathrm{(75 \% ).}$

General Procedure for the Preparation of $\mathrm{Pc}$ Dimers. In a typical experiment DHPc $(2 \mathrm{~g}$, $3.48 \mathrm{mmol}$ ) was added to refluxing solution of DCPc $(2.24 \mathrm{~g}, 3.36 \mathrm{mmol})$ and quinoline $(125 \mathrm{ml})$. After refluxing $2.5 \mathrm{~h}$ under nitrogen atmosphere the mixture was filtered, washed with $100 \mathrm{ml}$ of $1: 1$ acetone/water mixture and dried. The solid was further treated with a mixture of $300 \mathrm{ml}$ of pyridine, $7.0 \mathrm{~g} \mathrm{NaOH}$ and $40 \mathrm{ml}$ of distilled water. After refluxing $30 \mathrm{~h}$, the resulting solution was cooled. The solid $\mathrm{DBPc}^{17}$ (crude) was filtered, washed with $50 \mathrm{ml}$ of $1: 1$ acetone/water mixture and dried under vacuum in a desiccator. Yield: $1.29 \mathrm{~g}$ (33\%). The crude DBPc $(1 \mathrm{~g}, 0.88 \mathrm{mmol})$ was capped with triethanolamine $(5 \mathrm{~g}, 33.5 \mathrm{mmol})$ following the procedure described above for the Pc monomer to afford $2 \mathbf{a}$. Yield: $0.78 \mathrm{~g}$ $(63 \%)$. 


\section{Thin Film Processing}

The films were made by casting a solution of a polyhydroxy derivative and isophorone diisocyanate (in such a proportion that the number of isocyanate groups would be equal to the number of hydroxyl groups) in dioxane followed by heating at $125^{\circ} \mathrm{C}$ for $1 \mathrm{~h}$. We also used triethanolamine (one-half molar equivalent of isophorone diisocyanate) as a processing aid to improve the quality of the films such as with respect to crack resistance.

\section{RESULTS AND DISCUSSION}

The structures of the polyhydroxy derivatives suitable for obtaining polyurethane films are shown in Figure 1. In order to obtain high yields of polyhydroxy derivatives and develop a generalized procedure for axial etherification using DHPc and DBPc, we modified the procedure reported for etherification of DHPc using a mono-functional alcohol. ${ }^{17,20,21} \mathrm{We}$ noted that on adding DHPc (or DBPc) into a refluxing solution of a poly-functional alcohol and pyridine (twenty times and equivalent molar amount, respectively) in a high boiling solvent such as $o$-dichlorobenzene (o-DCB), the desired product in high yield obtained in less than one hour. Since the starting material, DHPc (or DBPc), was insoluble in common organic solvents the product obtained was reasonably pure (ca. 95\%) after work-up. Further purification of the derivatives was perfomed by dissolving in chloroform and precipitating from hexane. Purification using column chromatography was fruitless due to decomposition of the product. In general, liquid alcohols afforded higher yields than did solid ones. Analytical data of both monomers $(\mathbf{1 a}-\mathbf{c})$ and dimers $(\mathbf{2} \mathbf{a}-\mathbf{c})$ are presented in Table I. The FT-IR bands at 830 and 3535 $\mathrm{cm}^{-1}$ due to $\mathrm{Si}-\mathrm{O}-\mathrm{H}$ group observed in both DHPc and DBPc were absent in the monomers and dimers. Instead, a new sharp band appeared at $3435 \mathrm{~cm}^{-1}$ due to aliphatic hydroxyl groups. The major difference in the FT-IR spectra of the monomers and dimers was the presence of a sharp band at $988 \mathrm{~cm}^{-1}$ due to $-\mathrm{Si}-\mathrm{O}-\mathrm{Si}$ bond in the dimers. The IR absorptions attributed to the Pc ring in both monomers and dimers in the $1150-650 \mathrm{~cm}^{-1}$ range remained essentially unchanged.

Some derivatives have emerged as the best

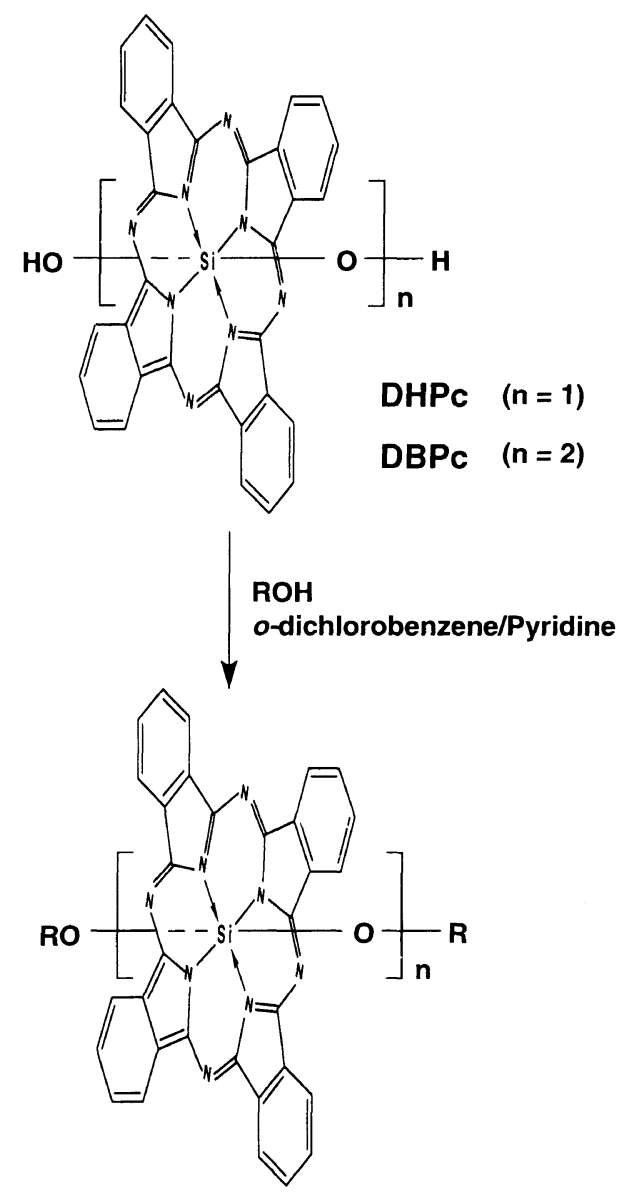

\begin{tabular}{cll}
\hline \multicolumn{2}{l}{ Compound } & $n$ \\
\hline 1a & $\mathrm{CH}_{2} \mathrm{CH}_{2} \mathrm{~N}_{\left(\mathrm{CH}_{2} \mathrm{CH}_{2} \mathrm{OH}\right)_{2}}$ & 1 \\
1b & $\mathrm{CH}_{2} \mathrm{CH}_{2} \mathrm{OCH}_{2} \mathrm{CH}_{2} \mathrm{OCH}_{2} \mathrm{CH}_{2} \mathrm{OH}$ & 1 \\
& & \\
1c & $\mathrm{CH}_{2} \mathrm{CH}_{2} \mathrm{~N}_{\left(\mathrm{CH}_{2} \mathrm{CH}_{2} \mathrm{OH}\right) \mathrm{CO}}$ & $\mathbf{1}$ \\
2a & Same as 1a & 2 \\
2b & Same as 1b & 2 \\
2c & Same as 1c & \\
\hline
\end{tabular}

Figure 1. Synthesis of monomers and dimers. 
A. K. Sinha and B. K. Mandal

Table I. Analytical data of monomers and dimers

\begin{tabular}{|c|c|c|c|c|c|c|c|}
\hline \multirow{2}{*}{ Compound } & \multirow{2}{*}{$\frac{\text { Yield }}{\%}$} & & \multicolumn{3}{|c|}{ Analysis } & \multirow{2}{*}{$\frac{{ }^{1} \mathrm{H} \mathrm{NMR}\left(\mathrm{CDCl}_{3}\right)}{\delta / \mathrm{ppm}}$} & \multirow{2}{*}{$\begin{array}{c}\text { FAB-MS } \\
m / z\end{array}$} \\
\hline & & & $\mathrm{C} / \%$ & $\mathrm{H} / \%$ & $\mathrm{~N} / \%$ & & \\
\hline $1 \mathbf{a}$ & 75 & $\begin{array}{l}\text { Exptl } \\
\text { Calcd }\end{array}$ & $\begin{array}{l}63.51 \\
63.14\end{array}$ & $\begin{array}{l}4.98 \\
5.30\end{array}$ & $\begin{array}{l}16.69 \\
16.73\end{array}$ & $\begin{array}{l}-2.02(\mathrm{t}, 4 \mathrm{H}),-0.22(\mathrm{t}, 4 \mathrm{H}), 0.85(\mathrm{t}, 8 \mathrm{H}) \\
1.99(\mathrm{t}, 8 \mathrm{H}), 8.37(\mathrm{~m}, 8 \mathrm{H}), 9.68(\mathrm{~m}, 8 \mathrm{H})\end{array}$ & $837,688,557$ \\
\hline 1b & 84 & $\begin{array}{l}\text { Exptl } \\
\text { Calcd }\end{array}$ & $\begin{array}{l}63.33 \\
62.99\end{array}$ & $\begin{array}{l}5.03 \\
5.05\end{array}$ & $\begin{array}{l}13.12 \\
13.36\end{array}$ & $\begin{array}{l}-1.89(\mathrm{t}, 4 \mathrm{H}), 0.49(\mathrm{t}, 4 \mathrm{H}), 2.43(\mathrm{~m}, 8 \mathrm{H}) \\
2.95(\mathrm{t}, 4 \mathrm{H}), 3.32(\mathrm{t}, 4 \mathrm{H}), 8.36(\mathrm{~m}, 8 \mathrm{H}) \\
9.66(\mathrm{~m}, 8 \mathrm{H})\end{array}$ & $839,689,556$ \\
\hline 1c & 70 & $\begin{array}{l}\text { Exptl } \\
\text { Calcd }\end{array}$ & $\begin{array}{l}64.97 \\
65.12\end{array}$ & $\begin{array}{l}4.55 \\
4.41\end{array}$ & $\begin{array}{l}17.58 \\
17.52\end{array}$ & $\begin{array}{l}-2.0(\mathrm{t}, 4 \mathrm{H}),-1.71(\mathrm{t}, 4 \mathrm{H}), 0.52(\mathrm{t}, 4 \mathrm{H}) \\
1.27(\mathrm{t}, 4 \mathrm{H}), 8.39(\mathrm{~m}, 8 \mathrm{H}), 8.66(\mathrm{~m}, 4 \mathrm{H}) \\
9.04(\mathrm{~m}, 4 \mathrm{H}), 9.67(\mathrm{~m}, 8 \mathrm{H})\end{array}$ & $\begin{array}{l}959,854,749 \\
556\end{array}$ \\
\hline $2 a$ & 63 & $\begin{array}{l}\text { Exptl } \\
\text { Calcd }\end{array}$ & $\begin{array}{l}65.21 \\
65.50\end{array}$ & $\begin{array}{l}4.58 \\
4.34\end{array}$ & $\begin{array}{l}17.98 \\
18.09\end{array}$ & $\begin{array}{l}-3.70(\mathrm{t}, 4 \mathrm{H}),-1.26(\mathrm{t}, 4 \mathrm{H}), 0.00(\mathrm{t}, 8 \mathrm{H}),^{\mathrm{a}} \\
1.28(\mathrm{t}, 8 \mathrm{H}), 8.34(\mathrm{~m}, 8 \mathrm{H}), 9.05(\mathrm{~m}, 8 \mathrm{H})\end{array}$ & - \\
\hline $\mathbf{2 b}$ & 72 & $\begin{array}{l}\text { Exptl } \\
\text { Calcd }\end{array}$ & $\begin{array}{l}65.33 \\
65.41\end{array}$ & $\begin{array}{l}4.36 \\
4.19\end{array}$ & $\begin{array}{l}15.98 \\
16.06\end{array}$ & $\begin{array}{l}-3.62(\mathrm{t}, 4 \mathrm{H}),-0.61(\mathrm{t}, 4 \mathrm{H}), 2.46(\mathrm{~m}, 8 \mathrm{H}) \\
2.94(\mathrm{t}, 4 \mathrm{H}), 3.62(\mathrm{t}, 4 \mathrm{H}), 8.34(\mathrm{~m}, 8 \mathrm{H}) \\
9.04(\mathrm{~m}, 8 \mathrm{H})\end{array}$ & - \\
\hline $2 c$ & 62 & $\begin{array}{l}\text { Exptl } \\
\text { Calcd }\end{array}$ & $\begin{array}{l}66.37 \\
66.51\end{array}$ & $\begin{array}{l}4.05 \\
3.85\end{array}$ & $\begin{array}{l}18.68 \\
18.55\end{array}$ & $\begin{array}{l}-3.61(\mathrm{t}, 4 \mathrm{H}),-3.45(\mathrm{t}, 4 \mathrm{H}), 0.46(\mathrm{t}, 4 \mathrm{H}) \\
1.25(\mathrm{t}, 4 \mathrm{H}), 8.08(\mathrm{~m}, 8 \mathrm{H}), 8.32(\mathrm{~m}, 4 \mathrm{H}) \\
8.39(\mathrm{~m}, 4 \mathrm{H}), 9.03(\mathrm{~m}, 8 \mathrm{H})\end{array}$ & - \\
\hline
\end{tabular}

${ }^{\text {a }}$ Signal merged with TMS. The triplet was apparent in the expanded spectrum.

Table II. Electronic spectra ${ }^{a}$ and solublilities of monomers and dimers

\begin{tabular}{|c|c|c|c|c|c|c|}
\hline \multirow{2}{*}{ Compound } & \multicolumn{5}{|c|}{ Wavelength } & \multirow{2}{*}{$\frac{\text { Solubility }^{\mathrm{b}}}{\mathrm{gm} \mathrm{l}^{-1}}$} \\
\hline & \multicolumn{5}{|c|}{$\mathrm{nm}\left(10^{-4} \varepsilon, \mathrm{mol}^{-1} \mathrm{~cm}^{-1}\right)$} & \\
\hline $1 \mathbf{a}$ & $677(21.1084)$ & $649(2.9795)$ & $610(3.3731)$ & $356 \quad(6.9402)$ & $288 \quad(2.1438)$ & $121.5(0.145)$ \\
\hline $1 b$ & $674(17.9275)$ & $645(2.3412)$ & $607(2.7461)$ & 353 (5.3799) & $280 \quad(1.7930)$ & $64.0(0.076)$ \\
\hline $1 c$ & $677(12.8583)$ & 638 (4.5367) & $610(2.7112)$ & $355 \quad(5.4310)$ & $289 \quad(2.2720)$ & $143.0(0.149)$ \\
\hline $2 \mathbf{a}$ & $635(33.158)$ & $587(5.5765)$ & $561(3.9954)$ & $331(16.8562)$ & $284(11.4221)$ & $38.6(0.028)$ \\
\hline $\mathbf{2 b}$ & $635(72.5280)$ & $588(1.9195)$ & $561(1.4425)$ & $330(43.1991)$ & $285(3.3188)$ & $11.8(0.008)$ \\
\hline $2 c$ & $636(20.1947)$ & $587(4.1231)$ & $562(3.0501)$ & $331(11.2921)$ & $284(6.9204)$ & $126.7(0.084)$ \\
\hline
\end{tabular}

${ }^{a}$ The electronic spectra were recorded in chloroform. ${ }^{b}$ Measured for a saturated solution at $25^{\circ} \mathrm{C}$, where $c=A / \varepsilon l$ and $l=1 \mathrm{~cm}$. Figures in the parentheses represent molarities of corresponding saturated solutions in $\mathrm{mol} \mathrm{L}^{-1}$.

known soluble phthalocyanine and bis-phthalocyanine derivatives (Table II). For instance, the solubility of compound 1a was measured at $12.1 \times 10^{-2} \mathrm{gm}$ per milliliter in chloroform $(\sim 0.15 \mathrm{M})$, which is about three times greater than that of previously reported soluble Pc derivatives. ${ }^{8,22,23)}$ Surprisingly, the derivatives generated from $N, N$-bis(2-hydroxyethyl isonicotinamide), 1c and 2c, showed incredibly high solubility in a variety of organic solvents such as chloroform. It is important to note that the previously reported phthalocyanine monomers and dimers derived from monofunctional alcohols such as $\mathrm{Si}\left[\mathrm{C}\left(\mathrm{CH}_{3}\right)_{3}\right]\left(\mathrm{CH}_{3}\right)_{2} \mathrm{OH}$ were soluble only in basic organic solvents such as pyridine and quinoline, and somewhat less soluble in polar solvents such as chloroform and dioxane. ${ }^{20}$

The most interesting feature of these derivatives is their facile processability into thin polyurethane films. The hydroxyl groups of these $\mathrm{Pc}$ derivatives react with a reactive 


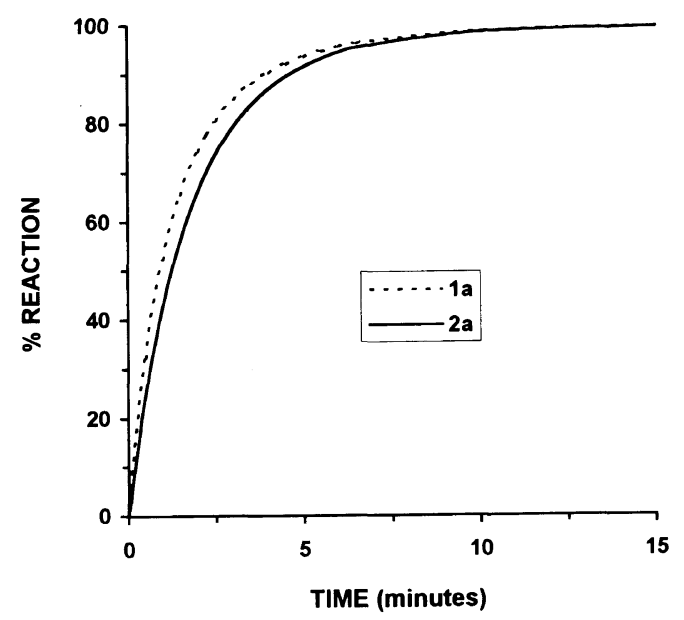

Figure 2. Kinetics of polymerization.

diisocyanate compound such as isophorone diisocyanate to form urethane linkages. The kinetics of polymerization using a representative example of each category are shown in Figure 2. Although both monomers and dimers require less than $10 \mathrm{~min}$ for complete conversion, we set the curing condition at $125^{\circ} \mathrm{C}$ for $1 \mathrm{~h}$ to ensure complete curing. The resulting polyurethane films possess high resistance to low impact scratches and thermostability at $125^{\circ} \mathrm{C}$ for over 10 hours.

FT-IR spectroscopy was also used to monitor curing of the films by observing the sharp peak at $2261 \mathrm{~cm}^{-1}$ due to $\mathrm{C} \equiv \mathrm{N}$ bond of the isocyanate group over time. The absorption peak gradually decreased with the progress of curing. The peak due to the $\mathrm{C}=\mathrm{O}$ bond of the isocyanate group which appeared at $1702 \mathrm{~cm}^{-1}$ was almost unchanged after curing. The disappearance of the $\mathrm{O}-\mathrm{H}$ band which appeared to overlap with the $\mathrm{N}-\mathrm{H}$ band in the 3100 $3700 \mathrm{~cm}^{-1}$ region was also noted as a result of the sharpening of the $\mathrm{N}-\mathrm{H}$ band at $3326 \mathrm{~cm}^{-1}$ (Figure 3).

Preliminary studies on polymer films (of about $1 \mu \mathrm{m}$ thickness) containing $23 \%$ by weight of phthalocyanine or bis-phthalocyanine derivatives indicate no observable microcrystallization or phase-segregation. The elec-

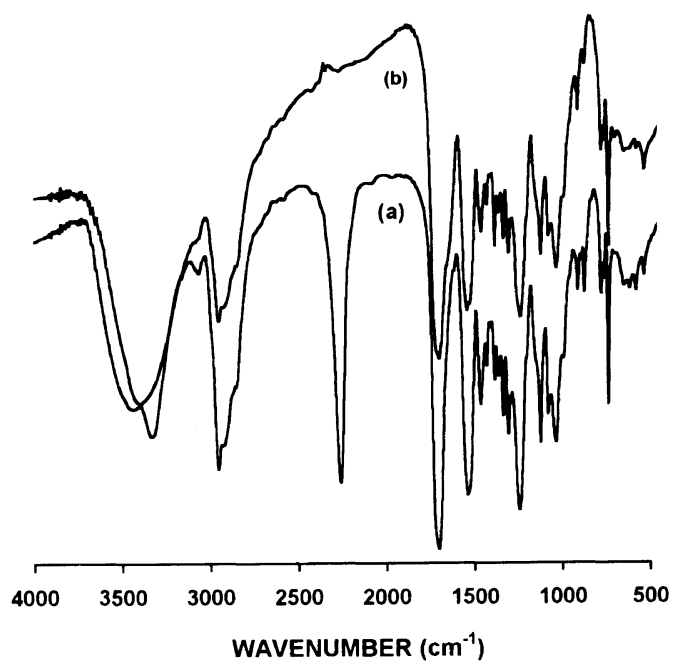

Figure 3. FT-IR spectra of compound $\mathbf{2 a}$, isophorone diisocyanate and triethanolamine mixture: (a) befor curing; (b) after curing.

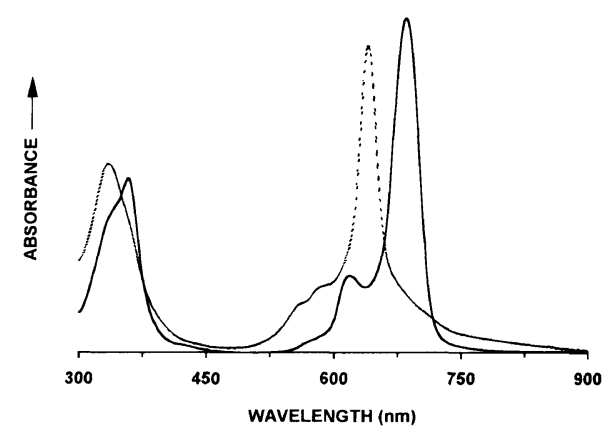

Figure 4. Electronic absorption spectra of polymer films (ca. $1 \mu \mathrm{m}$ thickness) containing $23 \%(\mathrm{w} / \mathrm{w})$ of compounds 1a (-) and 2 a (-.--).

tronic absorption spectra of the films also indicate high optical transparency in the visible region (Figure 4). Interestingly, Q- and B-band transitions of the dimers showed a dramatic shift to the blue region relative to the monomers, due to excitation coupling of neutral excitation transition between the Pc rings of the dimer. ${ }^{20}$

\section{CONCLUSIONS}

We developed a synthetic route for a new 
type of polyurethane films containing covalently attached phthalocyanine or bis-phthalocyanine rings in higher concentrations. To our knowledge, no bis-phthalocyanine derivative either covalently incorporated in a polyurethane matrix or highly soluble in common organic solvents has been reported thus far. Studies on the third-order nonlinear optical properties of the films as a function of the concentratios of the monomers and dimers will be published elsewhere.

Acknowledgments. The authors wish to thank Dr. B. Bihari and Dr. M. Kamath for their technical assistance, and Dr. K. Katti (University of Missouri) and Dr. T. Hsieh (Sandoz, Desplaines, Illinois) for their generous help in obtaining ${ }^{1} \mathrm{H}$ NMR and FAB-Mass spectra. This work is supported by the U. S. Army Tank-Automotive Command (Warren, Michigan) under the contract \#DAAE07-93C-R138. Acknowledgment is also made to AFOSR for providing funds (grant $\#$ F496209310-583) for the instruments used in this study.

\section{REFERENCES}

1. J. S. Shirk, J. R. Lindle, F. J. Bartoli, Z. H. Kafafi, and A. W. Snow, in "New Materials for Nonlinear Optics," S. R. Marder, J. E. Sohn, and G. D. Stucky, Ed., American Chemical Society, Washington, D.C. 1991, p 626.

2. M. Hosoda, T. Wada, T. Yamamoto, A. Kaneko, A. F. Garito, and H. Sasabe, Jpn. J. Appl. Phys., 31, 1071 (1992).

3. H. S. Nalwa, Adv. Mater., 5, 341 (1993).

4. B. K. Mandal, B. Bihari, A. K. Sinha, M. Kamath, and L. Chen, Appl. Phys. Lett., 66, 932 (1995).
5. P. A. Miles, Appl. Opt., 33, 6965 (1994).

6. C. Li, L. Zhang, M. Yang, H. Wang, and Y. Wang, Phys. Res. A, 49, 1149 (1994).

7. J. S. Shirk, R. G. S. Pong, F. J. Bartoli, and A. W. Snow, Appl. Phys. Lett., 63, 1880 (1993).

8. E. A. Cuellar and T. J. Marks, Inorg. Chem., 20, 3766 (1981).

9. M. Hanack, A. Gul, A. Hirsch, B. K. Mandal, L. R. Subramanian, and E. Witke, Mol. Cryst. Liq. Cryst., 187, 365 (1990).

10. M. Hosoda, T. Wada, A. Yamada, A. F. Garito, and H. Sasabe, Jpn. J. Appl. Phys., 30, 1715 (1991).

11. H. S. Nalwa, A. Kakuta, and A. Mukoh, Chem. Phy. Lett., 203, 109 (1993) and references therein.

12. H. S. Nalwa, A. Kakuta, and A, Mukoh, J. Phys. Chem., 97, 1097 (1993).

13. H. Hoshi, K. Kohama, S. Fang, and Y. Maruyama, Appl. Phys. Lett., 63, 3080 (1993).

14. T. Wada, Y. Matsuoka, K. Shigehara, A. Yamada, A. F. Garito, and H. Sasabe, in "Photoresponsive Materials," Vol. 12, Materials Research Society, Pittsburgh, PA, 1989, p 75.

15. J. S. Shirk, J. R. Lindle, F. J. Bartoli, Z. H. Kafafi, A. W. Snow, and M. E. Boyle, Int. J. Nonlinear Opt. Phys., 1, 699 (1992).

16. J. B. Davison and K. J. Wynne, Macromolecules, 11, 186 (1978).

17. B. L. Wheeler, G. Nagasubramanian, A. J. Bard, L. A. Schechtman, D. R. Dininny, and M. E. Kenney, J. Am. Chem. Soc., 106, 7404 (1984).

18. J. R. Sounik, G. Khanarian, J. Popolo, and S. Meyer, Chem. Mater., 5, 1253 (1993).

19. B. K. Mandal, A. K. Sinha, and M. Kamath, Polym. J., 27, 529 (1995) and references therein.

20. E. Ciliberto, K. A. Doris, W. J. Pietro, G. M. Reisner, D. E. Ellis, I. Fragala, F. H. Herbstein, M. A. Ratner, and T. J. Marks, J. Am. Chem. Soc., 106, 7748 (1984).

21. T. M. Mezza, N. R. Armstrong, G. W. Ritter, II, J. P. Iafalice, and M. E. Kenney, J. Electroanal. Chem., 137, 227 (1982).

22. V. Ahsen, E. Yilmazer, M. Ertas, and O. Bekaroblu, J. Chem. Soc., Dalton Trans., 401 (1988).

23. M. J. Cook, A. J. Dunn, S. D. Howe, and A. J. Thomson, J. Chem. Soc., Perkin Trans. 1, 2453 (1988). 